\title{
Fetal Sex Affects Expression of Renin-Angiotensin System Components in Term Human Decidua
}

\author{
Yu Wang, Kirsty G. Pringle, Shane D. Sykes, Francine Z. Marques, \\ Brian J. Morris, Tamas Zakar, and Eugenie R. Lumbers \\ School of Biomedical Sciences and Pharmacy (Y.W., K.G.P., S.D.S., E.R.L.), Mothers and Babies Research \\ Centre, and School of Medicine and Public Health (T.Z.), University of Newcastle, Hunter Medical \\ Research Institute and John Hunter Hospital, Newcastle, New South Wales 2300, Australia; and Basic \& \\ Clinical Genomics Laboratory (F.Z.M., B.J.M.), School of Medical Sciences and Bosch Institute, University \\ of Sydney, Sydney, New South Wales 2006, Australia
}

\begin{abstract}
The maternal decidua expresses the genes of the renin-angiotensin system (RAS). Human decidua was collected at term either before labor (i.e. cesarean delivery) or after spontaneous labor. The mRNA for prorenin $(R E N)$, prorenin receptor (ATP6AP2), angiotensinogen (AGT), angiotensinconverting enzymes 1 and 2 (ACE1 and ACE2), angiotensin II type 1 receptor (AGTR1), and angiotensin 1-7 receptor (MAS1) were measured by quantitative real-time RT-PCR. Decidual explants were cultured in duplicate for 24 and $48 \mathrm{~h}$, and all RAS mRNA, and the secretion of prorenin, angiotensin II, and angiotensin 1-7 was measured using quantitative real-time RT-PCR, ELISA, and radioimmunoassay, respectively. In the decidua collected before labor, REN mRNA levels were higher if the fetus was female. In addition, REN, ATP6AP2, AGT, and MAS1 MRNA abundance was greater in decidual explants collected from women carrying a female fetus, as was prorenin protein. After 24 h, ACE1 mRNA was higher in the decidual explants from women with a male fetus, whereas after $48 \mathrm{~h}$, both ACE1 and ACE2 mRNA was higher in decidual explants from women with a female fetus. Angiotensin II was present in all explants, but angiotensin 1-7 levels often registered below the lower limits of sensitivity for the assay. After labor, decidua, when compared with nonlaboring decidua, demonstrated lower REN expression when the fetus was female. Therefore, the maternal decidual RAS is regulated in a sex-specific manner, suggesting that it may function differently when the fetus is male than when it is female. (Endocrinology 153: 462-468, 2012)
\end{abstract}

$I_{p}$ $\mathrm{t}$ is becoming increasingly apparent that the outcome of pregnancy in relation to the health of the fetus and survival of the neonate is influenced by fetal sex. Several studies have shown that male fetuses have a higher risk of adverse pregnancy outcomes including spontaneous abortions (1), miscarriages later in pregnancy (2), stillbirths (3, $4)$, premature rupture of membranes and spontaneous preterm birth (5-8), gestational diabetes (9), and delivery by cesarean section $(7,10,11)$. In term deliveries, a higher proportion of preeclamptic pregnancies carry a male fetus $(5,9)$, whereas in preterm deliveries the proportion of females from preeclamptic pregnancies is higher $(5,10)$. Female babies are also more likely to be growth restricted

ISSN Print 0013-7227 ISSN Online 1945-7170

Printed in U.S.A.

Copyright (C) 2012 by The Endocrine Society

doi: 10.1210/en.2011-1316 Received May 31, 2011. Accepted October 6, 2011.

First Published Online November 1, 2011 than are males $(7,9)$. The causes of these differences are unknown, but it has been suggested that intrauterine tissues (and in particular the placenta) regulate fetal growth and survival in a sex-specific manner (12).

Renin is an enzyme secreted by the kidney that hydrolyzes angiotensinogen (AGT) to produce angiotensin I (Ang I), which in turn is cleaved by angiotensin-converting enzyme 1 (ACE1) to form angiotensin II (Ang II). The major actions of the renin-angiotensin system (RAS) are mediated via binding of Ang II to the Ang II type 1 receptor $\left(\mathrm{AT}_{1} \mathrm{R}\right)$. Ang II exerts opposing actions via the Ang II type 2 receptor $\left(\mathrm{AT}_{2} \mathrm{R}\right)(13)$. An angiotensin-converting enzyme homolog, angiotensin-converting enzyme 2 (ACE2),

Abbreviations: ACE1, Angiotensin-converting enzyme 1; ACE2, angiotensin-converting enzyme 2; AGT, angiotensinogen; Ang 1-7, angiotensin 1-7; Ang I, angiotensin I; Ang II, angiotensin II; $A T_{1} R$, Ang II type 1 receptor; $A T_{2} R$, Ang II type 2 receptor; (P)RR, (pro)renin receptor; RAS, renin-angiotensin system. 
can terminate the actions of Ang II by converting it to angiotensin 1-7 (Ang 1-7), which has effects that oppose those of Ang II and exerts these by binding to the protooncogene receptor (Mas) (14).

Until recently the precursor of renin, prorenin, was considered to have little biological activity, despite the fact that its circulating levels are 10 times higher than those of renin (15). The discovery of a (pro)renin receptor [(P)RR] that binds both renin and prorenin has changed this notion. Prorenin bound to (P)RR is active and can cleave AGT to Ang I. In addition, binding of prorenin to the (P)RR can induce intracellular signaling in its own right $(16,17)$.

Although the RAS is classically associated with the control of blood pressure, tissue-specific RAS have now been described in a number of organs not necessarily involved in blood pressure control (18-21). We have identified most of the RAS components in term human decidua, placenta, myometrium, and fetal membranes $(22,23)$. Although RAS proteins are found in human fetal membranes, expression of some of the RAS genes in these membranes is very low. For example, amnion contains an abundance of renin despite low renin (REN) mRNA (22). Interestingly, we have shown that decidua, a maternal tissue, expresses all of the known RAS genes $(22,23)$. Locally produced Ang II might affect the decidual microvasculature either by promoting angiogenesis or by altering vascular tone. Because decidual renin can escape into the maternal circulation (24), the decidual RAS may also play a role in maternal cardiovascular and renal homeostasis. Through these extrauterine and intrauterine actions, the decidual RAS could affect fetal development by altering embryonic access to nutrients.

Human recombinant renin has been shown to stimulate decidual production of prostaglandin-endoperoxide synthase 2, also known as cyclooxygenase-2 (25), a key enzyme involved in the initiation of labor. The release of prorenin from the decidua is constitutive, and the decidua is the major source of prorenin within the human uterus $(23,26)$. The decidual RAS could therefore play a role in the initiation of labor because the decidua is immediately adjacent to the myometrium.

We have developed a human decidual explant model to study the decidual RAS. This explant model provides the closest possible approximation to in vivo because freshly isolated tissue is used. This means that all cell types are present and in the same proportions at the end of $48 \mathrm{~h}$ of incubation as at the beginning. This is because the time elapsed is insufficient for any one cell type to outgrow the others. Furthermore, there is no evidence of increased cell death at $48 \mathrm{~h}$.

The aims of the present study were: 1) to determine whether the expression of decidual RAS genes was af- fected by fetal sex; 2) to define the expression of RAS genes in term human decidua collected before the onset of spontaneous labor by maintaining decidua in explant culture for 24 and $48 \mathrm{~h}$ ex vivo; and 3) to determine whether decidual explants could be used to study the control of expression of RAS genes and the secretion of prorenin and the angiotensin peptides Ang II and Ang 1-7. We also set out to determine whether the expression of decidual RAS genes is altered with labor.

\section{Materials and Methods}

\section{Tissue collection}

Decidual samples were collected as described previously (22, 23). All samples were collected from uncomplicated singleton pregnancies in women aged 19-39 yr. Decidual samples at term (37-40 wk gestation) delivered by elective cesarean section in the absence of labor were collected for the measurement of decidual gene expression $(\mathrm{n}=21)$. Additional samples were collected for decidual explants $(\mathrm{n}=6)$, and decidua was collected after spontaneous labor and vaginal delivery (38-41 wk gestation) for measurement of decidual RAS gene expression $(n=23)$. Women treated with nonsteroidal antiinflammatory drugs or who had a history of infection, chorioamnionitis, asthma, or preeclampsia or who were undergoing induction of labor were excluded. Informed consent was obtained from all participants, and the study was approved by the Hunter Area Research Ethics Committee and the University of Newcastle Human Research Ethics Committee. The fetal membranes and attached decidua parietalis were isolated as a whole, apart from a 2 -cm border at the edge of the placenta. Amnion was peeled from the choriodecidua, and chorion laevae were separated from the decidua by sharp dissection as described previously (27). Decidual tissue was then used in the decidual explant study or snap frozen in liquid nitrogen for subsequent RNA analyses.

\section{Decidual explant culture}

Entire excised deciduas were washed in tissue culture medium (phenol red free DMEM/F-12 supplemented with 15 mM HEPES, $1.2 \mathrm{~g} /$ liter $\mathrm{NaHCO}_{3}, 1 \mathrm{mg} / \mathrm{ml}$ L-glutathione reduced, $0.1 \mathrm{~g} /$ liter albumin fraction $\mathrm{V}, 0.65 \mu \mathrm{g} / \mathrm{ml}$ aprotinin, $10 \%$ fetal bovine serum, $40 \mu \mathrm{g} / \mathrm{ml}$ gentamicin) and dissected into approximately $0.25-\mathrm{cm}^{2}$ pieces. Several pieces of decidua were selected randomly, blotted, and weighed. One hundred milligrams of decidua were placed into each well of a six-well plate with $2 \mathrm{ml}$ of incubation medium. Decidual tissues and supernatants were collected after 24 and $48 \mathrm{~h}$ and snap frozen in liquid nitrogen for subsequent protein and mRNA analyses. Each experiment was conducted, in duplicate, using six separate decidual samples (three from women carrying a male and three from women carrying a female baby). Cell viability was verified by measuring lactate dehydrogenase release after incubation, as well as by measuring RNA stability and quality (data not shown).

The medium from decidual explant cultures was collected into EDTA tubes containing a protease inhibitor cocktail (Sigma, St. Louis, MO), and Ang II and Ang 1-7 concentrations were measured by RIA at ProSearch International Australia (Mel- 
bourne, Australia). Prorenin in the incubation medium was measured using the human prorenin ELISA kit (Molecular Innovations Inc., Novi, MI).

\section{Semiquantitative real-time RT-PCR}

Total RNA was isolated using TRIzol reagent according to the manufacturer's instructions (Invitrogen, Carlsbad, CA). RNA samples were treated with deoxyribonuclease (QIAGEN N.V., Hilden, Germany) before being reverse transcribed using a Superscript III reverse transcriptase kit with random hexamers (Invitrogen). Quantitative PCR was performed in an Applied Biosystems 7500 real-time PCR system using SYBR Green for detection (Applied Biosystems, Carlsbad, CA). Each reaction contained $5 \mu$ l of SYBR Green PCR master mix (Applied Biosystems), RAS primers as we have described previously $(22,23)$, cDNA reversed transcribed from $10 \mathrm{ng}$ total RNA, and water to $10 \mu \mathrm{l}$. mRNA abundance was calculated relative to $\beta$-actin $(A C T B)$ mRNA using the comparative $\mathrm{Ct}$ method as described previously $(22,23)$.

\section{RIA of Ang II and Ang 1-7}

Ang II was measured by direct RIA in plasma using the delayed tracer addition technique. Each sample of medium was equilibrated for $20 \mathrm{~h}$ at $4 \mathrm{C}$ in a total volume of $300 \mu \mathrm{l}$ with antibody raised in rabbit against angiotensin II N-terminally conjugated to bovine thyroglobulin. Monoiodinated ${ }^{125} \mathrm{I}$-angiotensin II, $10,000 \mathrm{cpm}$ in $100 \mu \mathrm{l}$, was added and allowed to equilibrate for a further $16 \mathrm{~h}$ at $4 \mathrm{C}$, after which the bound and free phases were separated using Dextran 10-coated charcoal and centrifugation. Sensitivity was $3.5 \mathrm{pg} / \mathrm{ml}$. Intra- and interassay coefficients of variation were 6.4 and $12 \%$, respectively.

Ang 1-7 was assayed directly by RIA using an antibody raised in guinea pig to Ang 1-7 N-terminally conjugated to porcine thyroglobulin and Ang 1-7 that had been monoiodinated with ${ }^{125}$ I antibody. Bound ${ }^{125}$ I-Ang $1-7$ was separated from free by dextran 10-coated charcoal, and unbound counts per minute were compared with serially diluted standard amounts of Ang 1-7. Sensitivity was $14 \mathrm{pg} / \mathrm{ml}$. Cross-reactivities to Ang I, Ang II, Ang III, and Ang IV were 0.11, 0.04, 0.53, and 0.03\%, respectively. Intra- and interassay coefficients of variation were 4.5 and $10 \%$, respectively.

\section{Measurement of prorenin protein by ELISA}

Prorenin in culture medium was measured using the human prorenin ELISA kit (Molecular Innovations) according to the manufacturer's instructions. Prorenin in each sample was captured by an antibody immobilized on to the surface of each well of the plate. A primary antibody specific for prorenin was then applied and the unbound fraction was removed by washings. For subsequent detection by means of color development, a secondary antibody conjugated to horseradish peroxidase 3,3,5,5tetramethylbenzidine substrate was added. After termination of the reaction with $4 \mathrm{M}$ sulfuric acid, OD was read at $450 \mathrm{~nm}$. Prorenin concentration was directly proportional to color development and was measured using a standard curve. Samples were assayed in duplicate. In our laboratory $1 \mathrm{ng} / \mathrm{ml}$ amniotic fluid prorenin measured using this technique generated $116 \mathrm{ng} /$ $\mathrm{h}^{-1} \cdot \mathrm{ml}^{-1}$ of Ang I from angiotensinogen present in nephrectomized sheep plasma used as the source of angiotensinogen substrate. All samples were assayed on one ELISA plate. There- fore, there was no interassay variability. Intraassay coefficient of variation was $7.3 \%$.

\section{Data analysis}

Decidual RAS gene expression data were tested using the nonparametric Mann-Whitney $U$ test. Decidual explant RAS gene expression data were tested for normality using the skewness and kurtosis test. The data set was found to be not normally distributed, so the data were logarithmically transformed. A univariate ANOVA with the patients' identification as a covariate was then used to test for differences in RAS mRNA abundance as a function of fetal sex and incubation time in decidual explants. An independent-sample $t$ test was used to determine the effects of fetal sex on prorenin, Ang II, and Ang 1-7 levels in the supernatant after $48 \mathrm{~h}$ ex vivo. The SPSS statistical package (SPSS for Windows, release 17.0.0; Chicago, IL) was used for all analyses. Significance was set at $P<0.05$.

\section{Results}

\section{The interaction between fetal sex and labor on decidual RAS expression}

The level of REN mRNA in maternal decidua from nonlaboring women was higher if the fetus was female $(P=0.011)$. Labor only affected decidual REN mRNA abundance when the fetus was female; the decidual $R E N$ mRNA level was lower after labor $(P=0.027)$, such that the significant sex-associated difference in $R E N$ mRNA abundance seen before labor was no longer present (Fig. 1).

There were no sex-specific effects, nor were there any interactions between fetal sex and labor on the expression of decidual AGT, ACE1, ACE2, AGTR1, and ATP6AP2 mRNA.

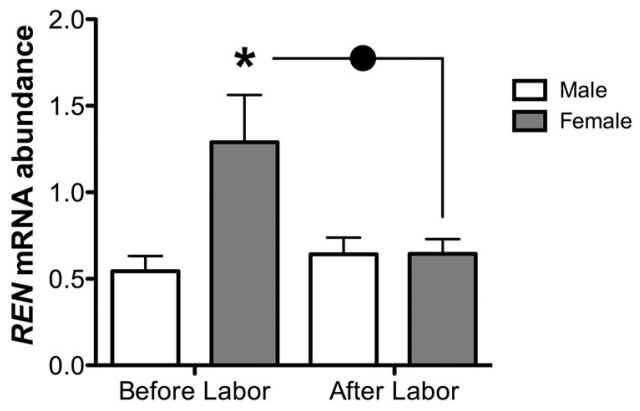

FIG. 1. Sex differences in REN mRNA abundance in maternal decidua collected before or after labor. Before labor decidual REN mRNA abundance was higher in women carrying a female fetus; after labor decidual REN levels no longer differed according to fetal sex because $R E N$ mRNA was lower in women with a female fetus after spontaneous labor compared with those not in labor. The $n$ value was 21 for before labor decidual samples ( $n=11$ for women carrying a male fetus and $n=10$ for women carrying a female fetus), and the $n$ value was 23 for after labor decidual samples ( $n=10$ for women carrying a male fetus and $n=13$ for women carrying a female fetus). The closed circle denotes the difference before and after labor $(P<$ 0.05). * , Significant difference between fetal sex $(P<0.05)$. 


\section{Effects of fetal sex on REN mRNA and protein levels in term decidua}

To determine whether the sex differences in decidual REN mRNA persisted in vitro, decidual explants were cultured for 24 or $48 \mathrm{~h}$. REN mRNA levels increased during incubation of decidual explants from women with a male fetus $(P=0.002)$. REN mRNA abundance was, however, significantly higher at 24 and $48 \mathrm{~h}$ in decidual explants from women with a female fetus compared with explants from women with a male fetus $(P=0.002$ and $P=0.010$, respectively; Fig. 2A).

Prorenin secretion into the explant supernatant, measured at $48 \mathrm{~h}$ ex vivo (over a $24 \mathrm{~h}$ incubation period), was significantly higher in the medium from explants of women with a female fetus $(P<0.05)$. Prorenin secretion into the medium for decidual explants from women carrying a female fetus was $4.9 \pm 0.95 \mathrm{ng} / \mathrm{ml}$ compared with $0.13 \pm 0.06 \mathrm{ng} / \mathrm{ml}$ in decidual explants from women carrying a male fetus (Fig. 2B).
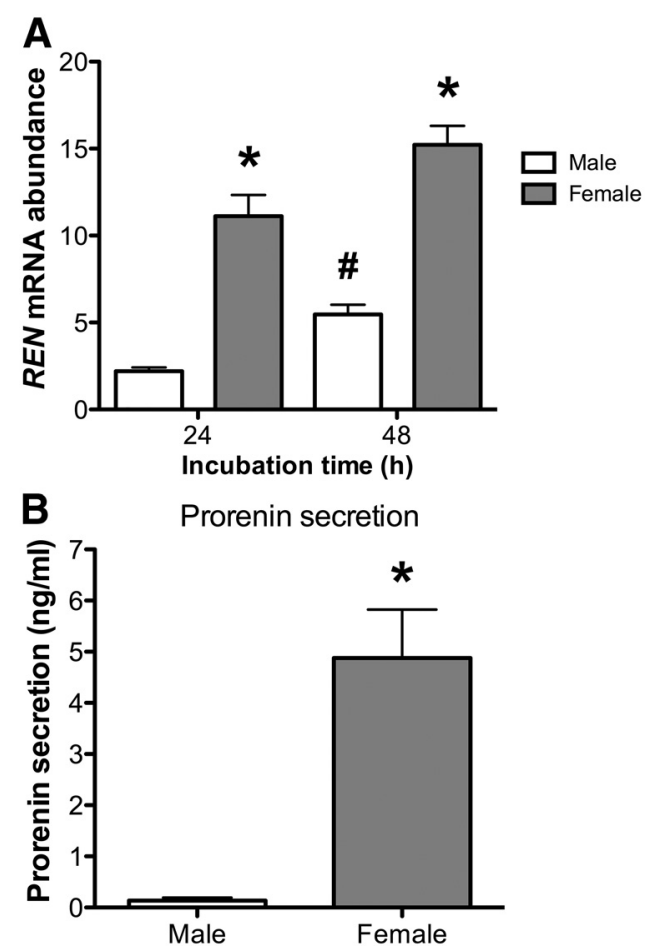

FIG. 2. Sex differences in REN mRNA abundance and prorenin secretion in decidual explants. REN mRNA levels were measured at 24 and $48 \mathrm{~h}$ of incubation. Prorenin was measured in medium collected from the second 24-h incubation period. A, After 24 and $48 \mathrm{~h}$ of incubation, decidual REN mRNA levels were higher in women carrying a female fetus. REN mRNA abundance in decidua increased with incubation time in decidua from women with a male fetus. B, The incubation medium from decidua of women with female fetuses contained significantly higher levels of prorenin than decidual explants from women with male fetuses. Data shown are for $n=4-6$ decidual explants collected from three different women per group. *, Significant difference between fetal sex $(P<0.05)$; $\#$, significant difference between incubation time within the same sex $(P<0.05)$.

\section{Effects of fetal sex on the expression of RAS mRNAs in decidual explants}

mRNA for the RAS genes AGT, ACE1, ACE2, AGTR1, ATP6AP2, and MAS1 were detected in decidual explants at 24 and $48 \mathrm{~h}$ of incubation (Fig. 3), whereas AGTR 2 mRNA was not. At 24 and $48 \mathrm{~h}$ of incubation, decidual mRNA levels of AGT, ATP6AP2, and MAS1 were all significantly higher in decidual explants from women with a female fetus than from women carrying a male fetus. ACE1 mRNA abundance was higher at $48 \mathrm{~h}$ of incubation in decidua from women with a female fetus than from women carrying a male fetus $(P=0.002)$. In contrast, the ACE2 mRNA expression was lower at $24 \mathrm{~h}$ $(P=0.041)$, but higher at $48 \mathrm{~h}(P=0.037)$, of incubation in decidua from women with a female fetus compared with women pregnant with male fetuses.

In decidual explants isolated from women carrying a male fetus, ACE1 mRNA levels decreased with incubation time $(P=0.010$; Fig. $3 \mathrm{~B})$. In decidual explants from women who were carrying a female fetus, the levels of ACE2 and ATP6AP2 mRNA increased with incubation time $(P=0.041$ and $P=0.010$, respectively; Fig. 3, C and E). AGTR1 mRNA abundance in decidual explants was not affected by either fetal sex or incubation time (Fig. 3D).

Decidual explant medium was changed every $24 \mathrm{~h}$; Ang II and Ang 1-7 levels were measured in medium collected from the second $24 \mathrm{~h}$ incubation. Measurable levels of Ang II were found (range of 6.9-134 pg/ml, $\mathrm{n}=6$ ), whereas Ang 1-7 levels in the medium were low, often registering below the lower limits of sensitivity of the assay (i.e. $<14$ $\mathrm{pg} / \mathrm{ml})$.

\section{Discussion}

The present study has revealed a striking effect of fetal sex on the expression of decidual REN mRNA. Subsequent tissue culture experiments confirmed and expanded our finding that the sex of the fetus determines the level of expression of several RAS mRNAs and the amount of prorenin secreted. In addition, we showed that decidual explants secrete both Ang II and Ang 1-7 into the culture supernatant, although we have not been able to determine whether the production of these peptides is influenced by fetal sex. These sex-associated differences in decidual REN mRNA expression and prorenin secretion provide new insights into the effects of fetal sex on adjacent tissues that are important for fetal growth and development, especially in early gestation. As mentioned in the introductory text, spontaneous abortions (1), miscarriages later in pregnancy $(2)$, stillbirths $(3,4)$, premature rupture of 
A

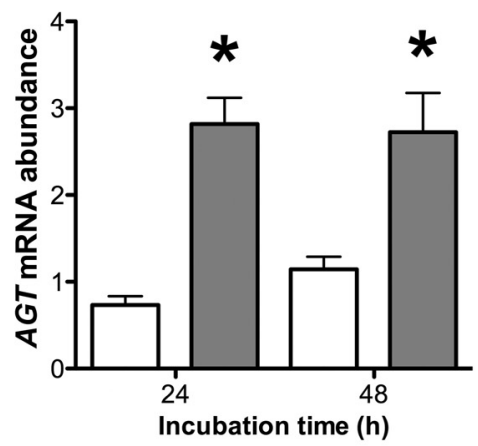

C

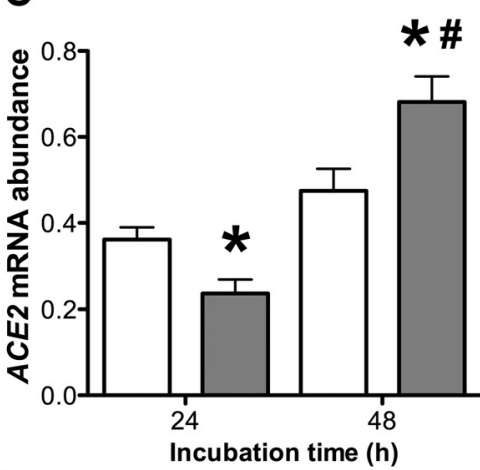

E

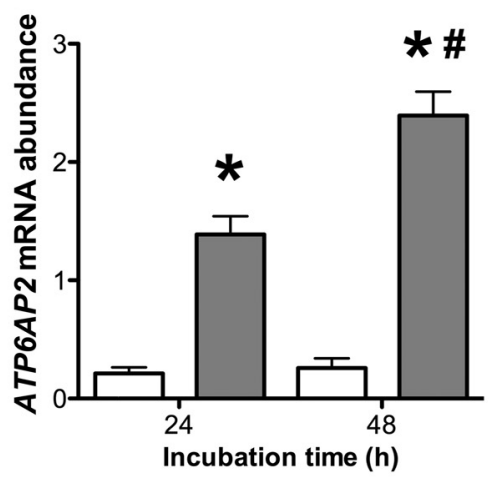

B

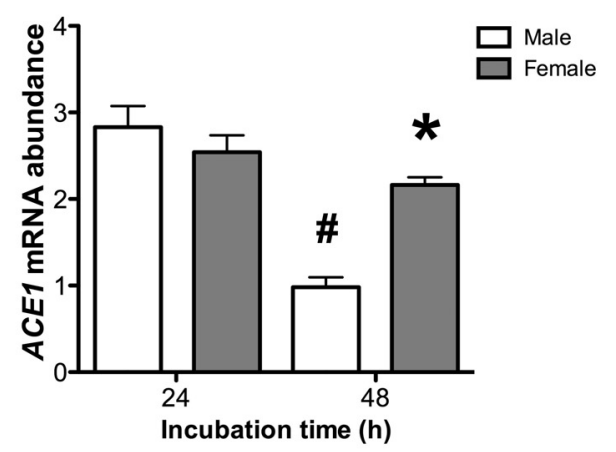

D

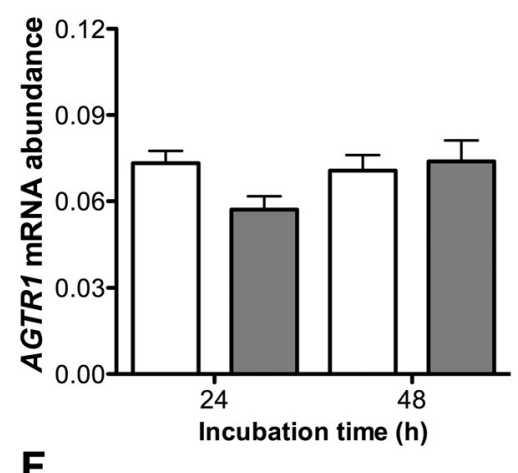

$\mathbf{F}$

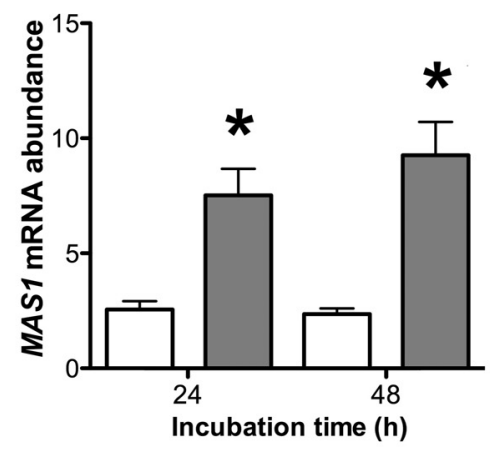

FIG. 3. Effects of fetal sex on mRNA levels for other genes in the RAS in human decidual explants incubated for 24 and $48 \mathrm{~h}$. A, AGT mRNA levels after 24 and $48 \mathrm{~h}$ incubation were higher in decidual explants from women with a female fetus $(P=0.002$ and $P=0.004)$. B, After $48 \mathrm{~h}$ incubation, ACE1 expression was higher in women with a female fetus $(P=0.002)$. ACE1 mRNA abundance in decidual explants from women with a male fetus decreased with incubation time $(P=0.01)$. C, ACE2 mRNA levels at $24 \mathrm{~h}$ incubation were lower in explants from women with a female fetus but were higher at $48 \mathrm{~h}$ of incubation $(P=0.041$ and $P=0.037)$. ACE2 mRNA abundance increased with incubation time for decidual explants from women with a female fetus $(P=0.041)$. D, AGTR1 mRNA abundance in decidual explants was not affected by either fetal sex or incubation time. E, Decidual ATP6AP2 mRNA levels were higher after 24 and $48 \mathrm{~h}$ of incubation for explants from women carrying a female fetus $(P<0.001$ and $P=0.002)$. ATP6AP2 expression was higher over the course of incubation for decidual explants from women with a female fetus ( $P=0.010)$. F, At 24 and $48 \mathrm{~h}$ of incubation, MAS1 expression was higher in explants from women with a female fetus $(P=0.005$ and $P<0.001)$. Values shown are for $n=4-6$ decidual explants collected from three women per group. * Significant difference between sex $(P<0.05)$; $\#$, significant difference between incubation time within the same $\operatorname{sex}(P<0.05)$.

pregnancies is more common in women carrying female fetuses $(5,10)$. Female babies are also more likely to be growth restricted $(7,9)$. All of these sex differences may be related to the effects of fetal sex on the decidual RAS because we believe that the decidual RAS is involved in regulating decidual angiogenesis and perhaps placental implantation. Therefore, these sex-specific effects on the decidual RAS expression and prorenin secretion may contribute to the sex differences reported in pregnancy outcomes cited above. Future studies on gene expression and protein synthesis in tissues of the uteroplacental unit should take into account the sex of the fetus because we have shown that fetal sex is able to alter gene expression in a maternal tissue (decidua).

It is unclear how sex-specific differences of decidual RAS expression affect pregnancy outcomes because there is currently no concrete knowledge of how the RAS functions within the decidua or how the decidua contributes its RAS products to the maternal circulation. However, it is clear that the sex differences in RAS genes seen in the decidua are unique because the fetal membranes and placenta do not show any sex-specific differences in RAS gene expression (22), even though these tissues are predominantly fetal in origin. Further investigation of the RAS in the myometrium may be warranted because the myometrium is a maternal tissue closely associated with the decidua.

In an attempt to better understand the effects of fetal sex on decidual RAS mRNA expression levels and subsequent protein secretion, we established human decidual explants. We were successful in maintaining decidua for $48 \mathrm{~h}$ ex vivo. The pattern of REN and AGTR1 expression within this explant model was similar to that seen in nonlaboring, nonincubated decidua (a difference and no difference membranes and spontaneous preterm birth (5-8), gestational diabetes (9), and delivery by cesarean section $(7,10$, 11 ) occur more frequently if the mother is carrying a male fetus, whereas the incidence of preeclampsia in preterm with fetal sex, respectively). In addition, decidual explants secreted prorenin, Ang II, and Ang 1-7 into the incubation medium, suggesting that the explant model is a valid model for the study of the human decidual RAS ex vivo. 
Not only did the sex of the fetus influence maternal decidual REN mRNA expression, but it also affected prorenin protein secretion by the decidua. This sex difference was maintained for up to $48 \mathrm{~h}$ ex vivo. Therefore, it is unlikely that fetal sex hormones were responsible for the difference. The persistence of the sex difference in expression and the emergence of increased expression of other RAS genes in decidua from women carrying a female fetus, suggest that decidual RAS gene expression is permanently altered by fetal sex. However, we have not as yet studied whether fetal sex affects the expression of the decidual/ placental RAS in early gestation.

Among the various late gestation human intrauterine tissues (fetal membranes, placenta, chorion, and myometrium), the decidua has the highest levels of REN mRNA $(22,23)$. High levels of prorenin (measured as enzyme activity after acid activation) have, however, been found in fetal membranes (28), and immunostaining for prorenin also shows that it is present in amnion and chorion as well as decidua and placenta (22). Because amnion and chorion express only very low levels of REN mRNA, it is likely that decidual prorenin is the source of the high levels of prorenin found in amniotic fluid $(22,23,26,29)$. Because we have shown that prorenin secretion by cultured decidua is significantly higher in pregnancies with female than with male fetuses, it is reasonable to conclude that levels of prorenin in amnion and in amniotic fluid may be higher when the fetus is female than when it is male.

The secretion of prorenin into the maternal circulation from the uteroplacental unit could also be influenced by fetal sex (24). Evidence for this can be seen in mice in which a human REN transgene was made to be expressed only in the placenta, yet human prorenin was found in maternal plasma (30). This demonstrates the ability of placental prorenin to enter the maternal bloodstream. Because we consistently found measurable levels of Ang II in decidual explants, it is tempting to speculate that decidual Ang II might be able to escape into the maternal circulation from early in gestation. As a consequence, the higher incidence of growth restriction in female neonates (7) may be related to higher prorenin and Ang II levels, causing vasoconstriction and reduced uteroplacental blood flow, possibly through down-regulation of $\mathrm{AT}_{2} \mathrm{R}$ within the uterine vasculature. We have, moreover, observed such a phenomenon when Ang II levels are raised in the pregnant ewe through exogenous infusion of Ang II for more than $24 \mathrm{~h} \mathrm{(31);} \mathrm{in} \mathrm{these} \mathrm{studies,} \mathrm{the} \mathrm{actions} \mathrm{of} \mathrm{Ang} \mathrm{II} \mathrm{on} \mathrm{AT}_{2} \mathrm{R}$ in the uterine vasculature of the sheep were able to offset the vasoconstrictor effects of Ang II mediated via the $\mathrm{AT}_{1} \mathrm{R}$ (31).

In this study, several decidual products of the RAS, prorenin and Ang peptides, were measured to determine whether the changes in expression of decidual RAS genes resulted in changes in the levels of their protein products or peptides. The high level of expression of REN mRNA was coupled with a high level of prorenin secretion from cultured decidua collected from women with a female fetus. Despite the striking difference in prorenin secretion and the up-regulation of expression of other RAS genes, it was not possible to demonstrate a sex difference in angiotensin peptide production, possibly because assays were performed on only six subjects (three male and three female) and the levels of the peptides were very low. In addition, there was degradation of these peptides, probably occurring concomitant with their production. Notwithstanding, it is still clear that an effect of fetal sex on the maternal decidua may be imprinted at an early stage of pregnancy, so that the differential expression of RAS components and the physiological and biochemical consequences of this may be present up to, but not after, labor.

Interestingly, it appears that the expression of decidual REN mRNA is down-regulated after labor (Fig. 1). If the decidual RAS plays a specific role in regulating the onset of labor, e.g. via stimulation of decidual prostaglandinendoperoxide synthase 2 production (25), then the suppression of REN mRNA if the fetus is female would counterbalance this action. Alternatively, it is possible that withdrawal of the decidual RAS could affect the integrity of the fetal membranes through a reduction in production of TGF- $\beta$ (32), which stimulates the formation of profibrotic molecules such as plasminogen activator inhibitor type 1 , fibronectin, and collagens (33), or through reduced activation of proinflammatory cytokines (34). These possibilities need to be tested in future studies.

In conclusion, the present study provides the first demonstration of a fetal sex-associated difference in expression of RAS genes in the maternal decidua. We have also shown that the changes in maternal decidual RAS gene expression that occur with labor depend on the sex of the fetus. Our data provide novel insights into the influences of fetal sex on decidual gene expression, in which the latter is important in supporting fetal growth and development. Our findings could contribute to understanding why there are significant differences in adverse pregnancy outcomes between female and male fetuses.

\section{Acknowledgments}

Dr. David Casely (Prosearch Pty. Ltd.) carried out the Ang II and Ang 1-7 RIA.

Address all correspondence and requests for reprints to: Dr. K. G. Pringle, Mothers and Babies Research Centre, Hunter 
Medical Research Institute, John Hunter Hospital, Locked Bag 1, Hunter Region Mail Centre, New South Wales 2310, Australia. E-mail: kirsty.pringle@newcastle.edu.au.

This work was supported by Project Grant 510746 from the National Health and Medical Research Council of Australia.

Disclosure Summary: Y.W., K.G.P., S.D.S., T.Z., and E.R.L. have nothing to declare. F.Z.M. and B.J.M. have received grant support from the National Health and Medical Research Council of Australia.

\section{References}

1. Byrne J, Warburton D 1987 Male excess among anatomically normal fetuses in spontaneous abortions. Am J Med Genet 26:605-611

2. Mizuno R 2000 The male/female ratio of fetal deaths and births in Japan. Lancet 356:738-739

3. Engel PJ, Smith R, Brinsmead MW, Bowe SJ, Clifton VL 2008 Male sex and pre-existing diabetes are independent risk factors for stillbirth. Aust N Z J Obstet Gynaecol 48:375-383

4. Smith GC 2000 Sex, birth weight, and the risk of stillbirth in Scotland, 1980-1996. Am J Epidemiol 151:614-619

5. Vatten LJ, Skjaerven R 2004 Offspring sex and pregnancy outcome by length of gestation. Early Hum Dev 76:47-54

6. Cooperstock M, Campbell J 1996 Excess males in preterm birth: interactions with gestational age, race, and multiple birth. Obstet Gynecol 88:189-193

7. Melamed N, Yogev Y, Glezerman M 2010 Fetal gender and pregnancy outcome. J Matern Fetal Neonatal Med 23:338-344

8. Zeitlin J, Saurel-Cubizolles MJ, De Mouzon J, Rivera L, Ancel PY, Blondel B, Kaminski M 2002 Fetal sex and preterm birth: are males at greater risk? Hum Reprod 17:2762-2768

9. Di Renzo GC, Rosati A, Sarti RD, Cruciani L, Cutuli AM 2007 Does fetal sex affect pregnancy outcome? Gender Med 4:19-30

10. Brettell R, Yeh PS, Impey LW 2008 Examination of the association between male gender and preterm delivery. Eur J Obstet Gynecol Reprod Biol 141:123-126

11. Lieberman E, Lang JM, Cohen AP, Frigoletto Jr FD, Acker D, Rao R 1997 The association of fetal sex with the rate of cesarean section. Am J Obstet Gynecol 176:667-671

12. Clifton VL 2010 Review: Sex and the human placenta: mediating differential strategies of fetal growth and survival. Placenta 31(Suppl):S33-S39

13. MacGregor GA, Markandu ND, Roulston JE, Jones JC, Morton JJ 1981 Maintenance of blood pressure by the renin-angiotensin system in normal man. Nature 291:329-331

14. Sampaio WO, Henrique de Castro C, Santos RA, Schiffrin EL, Touyz RM 2007 Angiotensin-(1-7) counterregulates angiotensin II signaling in human endothelial cells. Hypertension 50:1093-1098

15. Derkx FH, Alberda AT, de Jong FH, Zeilmaker FH, Makovitz JW, Schalekamp MA 1987 Source of plasma prorenin in early and late pregnancy: observations in a patient with primary ovarian failure. J Clin Endocrinol Metab 65:349-354

16. Nguyen G, Delarue F, Burckl é C, Bouzhir L, Giller T, Sraer JD 2002 Pivotal role of the renin/prorenin receptor in angiotensin II production and cellular responses to renin. J Clin Invest 109:1417-1427

17. Saris JJ, 't Hoen PA, Garrelds IM, Dekkers DH, den Dunnen JT, Lamers JM, Jan Danser AH 2006 Prorenin induces intracellular signaling in cardiomyocytes independently of angiotensin II. Hypertension 48:564-571

18. Cooper AC, Robinson G, Vinson GP, Cheung WT, Broughton Pipkin $\mathrm{F} 1999$ The localization and expression of the renin-angiotensin system in the human placenta throughout pregnancy. Placenta 20: 467-474

19. Dostal DE, Baker KM 1999 The cardiac renin-angiotensin system: conceptual, or a regulator of cardiac function? Circ Res 85:643-650

20. Engeli S, Negrel R, Sharma AM 2000 Physiology and pathophysiology of the adipose tissue renin-angiotensin system. Hypertension 35:1270-1277

21. Wagner J, Jan Danser AH, Derkx FH, de Jong TV, Paul M, Mullins JJ, Schalekamp MA, Ganten D 1996 Demonstration of renin mRNA, angiotensinogen mRNA, and angiotensin converting enzyme mRNA expression in the human eye: evidence for an intraocular renin-angiotensin system. Br J Ophthalmol 80:159-163

22. Marques FZ, Pringle KG, Conquest A, Hirst JJ, Markus MA, Sarris M, Zakar T, Morris BJ, Lumbers ER 2011 Molecular characterization of renin-angiotensin system components in human intrauterine tissues and fetal membranes from vaginal delivery and cesarean section. Placenta 32:214-221

23. Pringle KG, Zakar T, Yates D, Mitchell CM, Hirst JJ, Lumbers ER 2011 Molecular evidence of a (pro)renin/(pro)renin receptor system in human intrauterine tissues in pregnancy and its association with PGHS-2. J Renin Angiotensin Aldosterone Syst 12:304-310

24. Brar HS, Do YS, Tam HB, Valenzuela GJ, Murray RD, Longo LD, Yonekura ML, Hsueh WA 1986 Uteroplacental unit as a source of elevated circulating prorenin levels in normal pregnancy. Am J Obstet Gynecol 155:1223-1226

25. Mitchell MD, Edwin SS, Pollard JK, Trautman MS 1996 Renin stimulates decidual prostaglandin production via a novel mechanism that is independent of angiotensin II formation. Placenta 17: 299-305

26. Shaw KJ, Do YS, Kjos S, Anderson PW, Shinagawa T, Dubeau L, Hsueh WA 1989 Human decidua is a major source of renin. J Clin Invest 83:2085-2092

27. Johnson RF, Mitchell CM, Clifton V, Zakar T 2004 Regulation of 15-hydroxyprostaglandin dehydrogenase (PGDH) gene activity, messenger ribonucleic acid processing, and protein abundance in the human chorion in late gestation and labor. J Clin Endocrinol Metab 89:5639-5648

28. Skinner SL, Lumbers ER, Symonds EM 1968 Renin concentration in human fetal and maternal tissues. Am J Obstet Gynecol 101:529533

29. Lumbers ER 1971 Activation of renin in human amniotic fluid by low pH. Enzymologia 40:329-336

30. Takimoto E, Ishida J, Sugiyama F, Horiguchi H, Murakami K, Fukamizu A 1996 Hypertension induced in pregnant mice by placental renin and maternal angiotensinogen. Science 274:995-998

31. McMullen JR, Gibson KJ, Lumbers ER, Burrell JH, Wu J 1999 Interactions between AT1 and AT2 receptors in uterine arteries from pregnant ewes. Eur J Pharmacol 378:195-202

32. Schuster N, Krieglstein K 2002 Mechanisms of TGF- $\beta$-mediated apoptosis. Cell Tissue Res 307:1-14

33. Jan Danser AH, Batenburg WW, van Esch JH 2007 Prorenin and the (pro)renin receptor - an update. Nephrol Dial Transplant 22:12881292

34. Keelan JA, Wang K, Chaiworapongsa T, Romero R, Mitchell MD, Sato TA, Brown DA, Fairlie WD, Breit SN 2003 Macrophage inhibitory cytokine 1 in fetal membranes and amniotic fluid from pregnancies with and without preterm labour and premature rupture of membranes. Mol Hum Reprod 9:535-540 